\title{
Britain spends to secure scientific growth
}

Jim Giles, London

UK researchers will find more money in the coffers of those funding them over the next three years, thanks to spending plans announced by the government on 12 July.

The plans call for the country's two main science-funding streams, which cater for basic research grants and university running costs, to be boosted by $5.8 \%$ a year in real terms between 2004-05 and 2007-08. That does not quite match the $10 \%$ annual increases called for in the previous 2002 spending review (see Nature 418, 261; 2002) and seen over the past few years. But it will still take government funding for science and engineering to $\mathfrak{E} 5$ billion (US $\$ 9.3$ billion) annually, up from

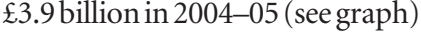

The figures, unveiled by the chancellor of the exchequer, Gordon Brown, as part of a tenyear science strategy, were accompanied by a slew of smaller measures that will also find favour among researchers. An extra $£ 80$ million over three years has been allocated to help fund salaries associated with basic research grants, for example, easing complaints that these costs were being ignored by funders.

"There is much in this that appears to be genuinely good news for the science community," says Peter Cotgreave, director of the pressure group Save British Science. More good tidings were supplied by the Wellcome Trust. To coincide with the chancellor's speech, the medical charity has announced that it will invest $\mathfrak{E} 1.5$ billion (US $\$ 2.8$ billion) in Britain
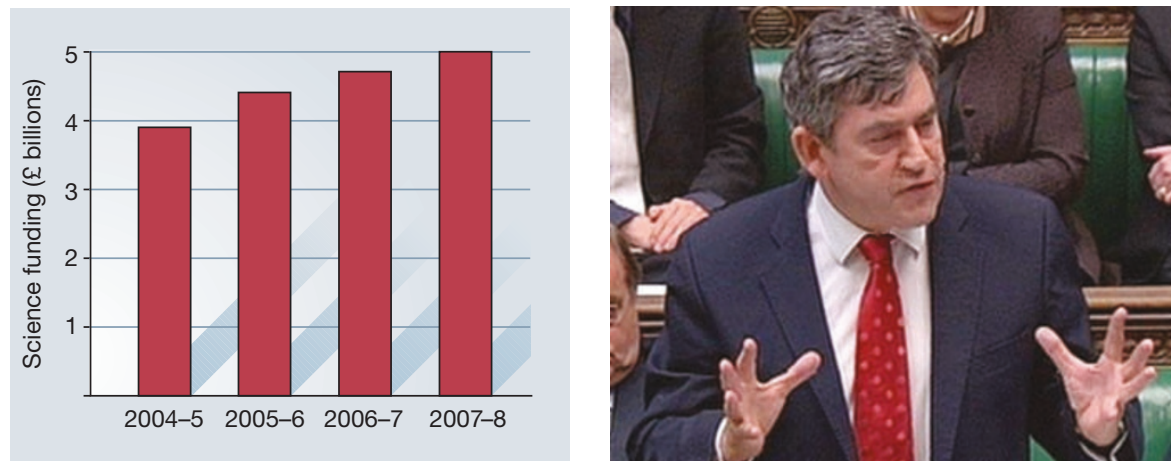

Hand out: Gordon Brown announces annual increases in funds for basic grants and university upkeep.

over the next five years, which will maintain its spending at current levels.

In the long term, Brown says he also hopes to raise combined government and business research and development funding from the current value of $1.9 \%$ of gross domestic product to $2.5 \%$ by 2014 . This ambitious target would bring Britain in line with competitors such as the United States and Germany which stand at $2.7 \%$ and $2.5 \%$, respectively. If this happens, and funding continues to rise at $5.8 \%$ over the next decade, the level of basic research grants may double as hoped (see Nature 429, 688; 2004). But Brown did not spell out which science-funding streams would be favoured under any future increases.

Critics question whether the strategy contains the new ideas needed to achieve this goal. Science-policy experts say that reaching the $2.5 \%$ target depends on increased privatesector funding. America's top 700 companies reinvest around $5 \%$ of money from sales into research and development, for example, but UK companies spend only half of that.

Yet the strategy focuses instead on boosting existing measures, such as grants to help universities work with industry. "There are no new fiscal measures and that is disappointing" says Cotgreave.

Lack of action on researchers' salaries was the other notable omission from the strategy. $\mathrm{PhD}$ stipends will remain frozen in real terms, although they have grown substantially over the past three years. Greater concern centres on pay for academics. It is unclear whether increases to the university-funding stream will be channelled away from infrastructure projects and into improved wages.

\section{Authors urged to come clean on competing interests}

\section{Jonathan Knight, San Francisco}

Many authors continue to keep financial conflicts of interest to themselves, despite ever stricter journal policies requiring full disclosure in published articles. That is the conclusion the Center for Science in the Public Interest (CSPI), a Washington-based pressure group, has reached after reviewing all the articles in four major medical research journals over a three-month period.

The problem is the result of a combination of lax enforcement by editors and loopholes in disclosure policies, says Merrill Goozner, a CSPI researcher and the author of the review. "Our study is a reminder that journals need to be vigilant," he says.

Concerns that researchers' financial interests might influence their objectivity or methods have been increasing for 20 years as ties between industry and the academic sphere have broadened. Yet research journals have been slow to respond. By 1997 , only $16 \%$ of the 1,400 top biomedical journals had any competing-interest disclosure policy in place, and enforcement was patchy at best (see Nature 411,$3 ; 2001$ )

Goozner examined articles published from December 2003 to February 2004 in the New England Journal of Medicine, the Journal of the American Medical Association, Environmental Health Perspectives and Toxicology and Applied Pharmacology. He used websites and public databases to investigate the lead authors of each article in which a declaration of no competing interests was made. In a report released on 12 July, Goozner listed 13 studies, out of 163 , that failed to comply with the publishing journal's disclosure policy.

In one example, an author applied for a patent on a reagent that his paper suggested would be valuable in cancer research. In another, the authors on a paper about coronary heart disease were paid consultants to more than 20 companies in the heart-disease field, but did not disclose this. According to the CSPI report, the authors confirmed the relationships by e-mail, but said "None of them had anything to do with the paper. Why give them free advertising?"

Goozner says it should be up to the readers to decide. Because journals ask authors to declare only 'relevant' or 'directly relevant' ties, authors can too easily rationalize their omissions, he claims. Goozner's solution is to require disclosure of all ties to private firms and all patents regardless of relevance, and then let the editors decide which to publish.

The situation may be improving. Although it examined different journals, a 2001 study found that only $1 \%$ of papers disclosed a conflict (Sci. Eng. Ethics 7 , 205-218; 2001). In the current study, that rate was up to $20 \%$ of papers, with those failing to declare an interest making up only $8 \%$. That at least brings the problem into a manageable realm, says bioethicist Mildred Cho of Stanford University, California. "We should be able to deal with this in the future." 